\title{
Contrôle da Propaganda na Emprêsa Lucrativa Milton Lourenço*
}

Sumário: 1. Introdução. 2. Aumento nas Despesas de Propaganda. 3. Avaliaçäo dos Resultados. 4. Conclusão.

\section{Introdução}

No regime de concorrência, fazer propaganda é uma das decisões que o fabricante pode tomar. ${ }^{1}$ Contudo, ainda lavra a discórdia sôbre suas consequiências a curto e a longo prazo. Mormente en se tratando de uma política intensa ou agressiva, domina o temor de descaracterizar o produto, que passaria a se identificar com a propaganda, não fôsse, ainda, o receio de "estragar o mercado", açulando a concorrência a um tresloucado e aflitivo esfôrço de sobreviver, caminho para a ruína geral. Por isso, há emprêsas que buscam, sem o conseguir, o aparelhamento ideal de um contrôle adequado para ministrar a propaganda e analisar seus efeitos.

Optando por um modo simplificado de expor o assunto, queremos deixar entrever os passos que poderiam ser dados no estabelecimento dêsse contrôle. PEDERSEN encontra a solução no produto marginal de publicidade: "Por produto marginal de publicidade deve-se entender o acréscimo da quantidade de mercadorias vendidas que se obtém ao aumentar-se a soma de publicidade em um cruzeiro, ou, de maneira mais prática, em uma quantia maior (por exemplo, 100

- Economista e assessor econômico de emprêsas.

1 Stonier e Hague, in Teoria Economica, Zahar Editôres, 1959, p. 218. Já não se limita, portanto, à quantidade e preço do produto para o mercado.

R. Adı. Emp. Rio de Janeiro, 9 (2): 91-10, abr./jun. 1969 
cruzeiros), que se empregue como unidade para medir os progressos da atividade publicitária". ${ }^{2}$

Pedersen, no entanto, não ilustra sua explanação com um exemplo prático. Mesmo assim, para quem já lidou com cálculos marginais, não é difícil realizar uma adaptação de cunho pragmático um pouco fora da rigidez apresentada nos moldes teóricos.

Com o intuito de penetrar, analiticamente, no âmago dos resultados, inclinamo-nos pela atualização de receitas e custos, alicerçada numa estrutura de custos, porque, dessa forma, preservaríamos a sequiência ao longo da nova situação da emprêsa, ou, preliminarmente, favoreceríamos o exame antecipado da mesma, com um justo contrôle posterior.

São pontos capitais, então, a considerar:

I) Acima de tudo, o esquema metodológico:

a) em função dêle, o estádio de estagnação nas vendas é o instrumento auxiliar de que mais fàcilmente se poderia lançar mão para orientá-lo, o que, em absoluto, não torna a estagnação nas vendas condição indispensável à existência do contrôle de propaganda;

b) assim, também, quanto ao tratamento dado ao produto focalizado, sua caracterização pode ir transparecendo, por ser fabricado em série, para consumo final (mediato), e ser sucedâneo ou substitutivo, de outros produtos; porém, isto serve, a priori, à exposição, apenas em função do esquema metodológico.

II) Sôbre a orientação do esquema metodológico:

a) o contrôle de propaganda, como meio comparativo entre situações econômicas gerais;

b) a predominância da estrutura de custos e da procura mânifestatada no ordenamento, confronto e análise, unificando essas situações. 2 Pedersen, H. W. Los Costos y la Política de Precios, Madri, Aguilar,
1952, p. 94 e 95. 


\section{Aumento nas Despesas de Propaganda}

Vejamos o caso de uma companhia que, experimentando estagnação nas vendas de um produto por ela fabricado a um custo cada vez mais elevado, decidisse acrescer seus gastos de propaganda.$^{3} \mathrm{O}$ Quadro 1 evidencia a estagnação comprovada nos últimos cinco anos.

\section{QUADRO 1: Estagnação no Volume de Vendas do Produto 4 Quantidades Vendidas}

$\begin{array}{cc}\text { Anos } & \text { Unidades } \\ 1963 & 440.000 \\ 1964 & 430.000 \\ 1965 & 425.000 \\ 1966 & 440.000 \\ 1967 & 440.000\end{array}$

Obs.: Em 1964 e 1965 a produção (acompanhando as vendas) fôra ligeiramente inferior numa fase de recessão que atingiu vários ramos da indústria.

A Cúpula Administrativa tomou a decisão de despender mais em propaganda a partir de uma pesquisa de mercado, realizada sob o comando da Divisão de Propaganda; nessa pesquisa concluiu-se que a nova geração de consumidores (possíveis) ou não havia tomado conhecimento do produto, ou não se interessava em adquiri-lo.

Foi acolhido parecer da Assessoria Econômica para que o preço unitário se conservasse em $\mathrm{NCr} \$ 25,00$ pelo espaço mínimo de três meses. Tendo a Assessoria Econômica a seu cargo o contrôle dos resultados da propaganda, estabeleceu um período experimental de seis meses, de janeiro a junho, durante o qual as quantias levadas à conta de propaganda seriam variáveis.

A Assessoria Econômica fundou seu parecer nos seguintes pontos:

a) O mercado é típico de concorrência, porém não muito fragmentado ou esparso, e sem a perspectiva de ingresso de novos concorrentes nos próximos doze meses;

3 Não está em discussão, pròpriamente, a modalidade de propaganda eleita.

1 Nesse e nos outros quadros, os números são fictícios, mas inspirados na observação de fatos reais em várias emprêsas. 
b) As vendas não são influenciadas por variação estacional; apresentam curso regular mês a mês, exceto no rush de novembro e dezembro, com alguns reflexos em janeiro;

c) A oferta e a procura, em princípio, são elásticas.

A pedido da Assessoria Econômica, a Divisão de Custos extraiu os quocientes percentuais da relação Custos de Fabricação + Despesas/Receita de Vendas nos anos de 1963 a 1967, tendo-se verificado os seguintes resultados:

$\begin{array}{cc}\text { QUADRO 2: Evolução dos Custos sôbre a Receita do Produto } \\ \text { Anos } & \% \\ 1963 & 80 \\ 1964 & 82 \\ 1965 & 88 \\ 1966 & 90 \\ 1967 & 93\end{array}$

Informou ainda a Divisão de Custos que a atual composição do custo dos produtos vendidos era a seguinte:

QUADRO 3: Estrutura Simples do Atual Custo dos Produtos Vendidos

1. Custo de Fabricação $50 \%$

2. Despesas de Vendas $30 \%$

3. Despesas de Administração $20 \%$

$100 \%$

As opções que se ofereciam à companhia eram a redução de custos ou o aumento da procura para seu produto. Desejando sair da situação em que se achava mergulhada, inclinou-se pela segunda alternativa, porquanto era problemático o êxito da redução de custos, uma vez que, de início, já era muito limitado seu poder de compra junto aos fornecedores.

De posse dos volumes de vendas de 1963 a 1967 e dos elementos que lhe foram fornecidos pela Divisão de Custos, a Assessoria Econômica efetuou a atualização das receitas de vendas, ao preço unitário de $\mathrm{NCr} \$ 25,00$, e dos custos, em proporções correspondentes, para ulterior estudo e contrôle (Quadro 4). 
A atualização adotada busca a unificação necessária para a interpretação comparativa de duas fases da propaganda, ou mesmo, de duas situações econômicas da emprêsa, em têrmos de procura. Destarte, se a emprêsa hoje em dia detivesse idêntica procura, o panorama geral dos últimos cinco anos seria o apresentado, observados o preço unitário, a posição e a estrutura de custos atuais. Cria-se uma cabeça-de-ponte para investigação futura. O procedimento seguido foi o do equilíbrio das fôrças atuantes "no campo restrito da emprêsa", ou do mercado local, numa evolução da magnitude que foram tomando em face do resultado final. Como a perda do poder aqui-

QUADRO 4: Atualização das Receitas de Vendas e Custos ao Preço Unitário de $N C r \$ 25,00$ (EM NCr\$)

\begin{tabular}{|c|c|c|c|c|c|c|c|}
\hline Anos & $\begin{array}{l}\text { Receitas de } \\
\text { Vendas }\end{array}$ & $\begin{array}{l}\text { Custo de } \\
\text { Fabricaçajo }\end{array}$ & $\begin{array}{c}\text { Despesas de } \\
\text { Vendas }\end{array}$ & $\begin{array}{l}\text { Despesas de } \\
\text { Administração }\end{array}$ & $\begin{array}{l}\text { Total, Custos } \\
\text { e Despesas }\end{array}$ & $\begin{array}{l}\text { Resultado } \\
\text { Económico }\end{array}$ & $\begin{array}{c}\$ / \\
\text { Hec. }\end{array}$ \\
\hline $\begin{array}{l}1963 \\
1964 \\
1965 \\
1966 \\
1967\end{array}$ & $\begin{array}{l}11.000 .000,00 \\
10.750 .000,00 \\
10.625 .000,00 \\
11.000 .000,00 \\
11.000 .000,00\end{array}$ & $\begin{array}{l}4.400 .000,00 \\
4.407 .500,00 \\
4.675 .000,00 \\
4.950 .000,00 \\
5.115 .000,00\end{array}$ & $\begin{array}{l}2.640 .000,00 \\
2.644 .500 .00 \\
2.805 .000 .00 \\
2.970 .000,00 \\
3.069 .000,00\end{array}$ & $\begin{array}{l}1.760 .000,00 \\
1.763 .000,00 \\
1.870 .000,00 \\
1.980 .000,00 \\
2.046 .000,00\end{array}$ & $\begin{array}{r}8.800 .000,00 \\
8.815 .000,00 \\
9.350 .000,00 \\
9.900 .000,00 \\
10.230 .000,00\end{array}$ & $\begin{array}{r}+2.200 .000,00 \\
+1.935 .000,00 \\
+1.275 .000,00 \\
+1.100 .000,00 \\
+\quad 770.000,00\end{array}$ & $\begin{array}{r}20 \\
18 \\
12 \\
10 \\
7\end{array}$ \\
\hline
\end{tabular}

sitivo da moeda é fator condicionante da procura, encontra-se ela representada no crescimento dos custos - e, de maneira latente, na oscilação dos preços que teria acompanhado uma escala inflacionista. Assim, ao preço unitário da venda de $\mathrm{NCr} \$ 25,00$, mantida a procura, no presente, os custos permitem à emprêsa em questão um resultado econômico equivalente a apenas $7 \%$, sem arbitrariedades, isto é, por efeito de acomodação dos fatôres dentro do meio de operação onde atuam, nas várias relações com os mercados fornecedor, revendedor e consumidor. A questão fundamental é saber se a nova fase da propaganda é capaz de alterar a tendência de opressão ao resultado econômico. Isto tudo pode ser mais bem entendido através de exame do Gráfico 1. Variando $V$, terão variado as vendas reais, e, conservado o preço, estas dão idéia de prender-se qualquer variação ao tamanho da procura. Em V é sintomática a estagnação; não há, porém, estagnação dos custos em $\mathrm{C}$ - razão pela qual a atualização das despesas de propaganda, em têrmos de procura, mostra, no Quadro 5, que não se conseguiria impulsionar as vendas com NCr $\$ 300.000,00$ anuais, ou seja, o equivalente às despesas de propaganda efetuada em 1966. 


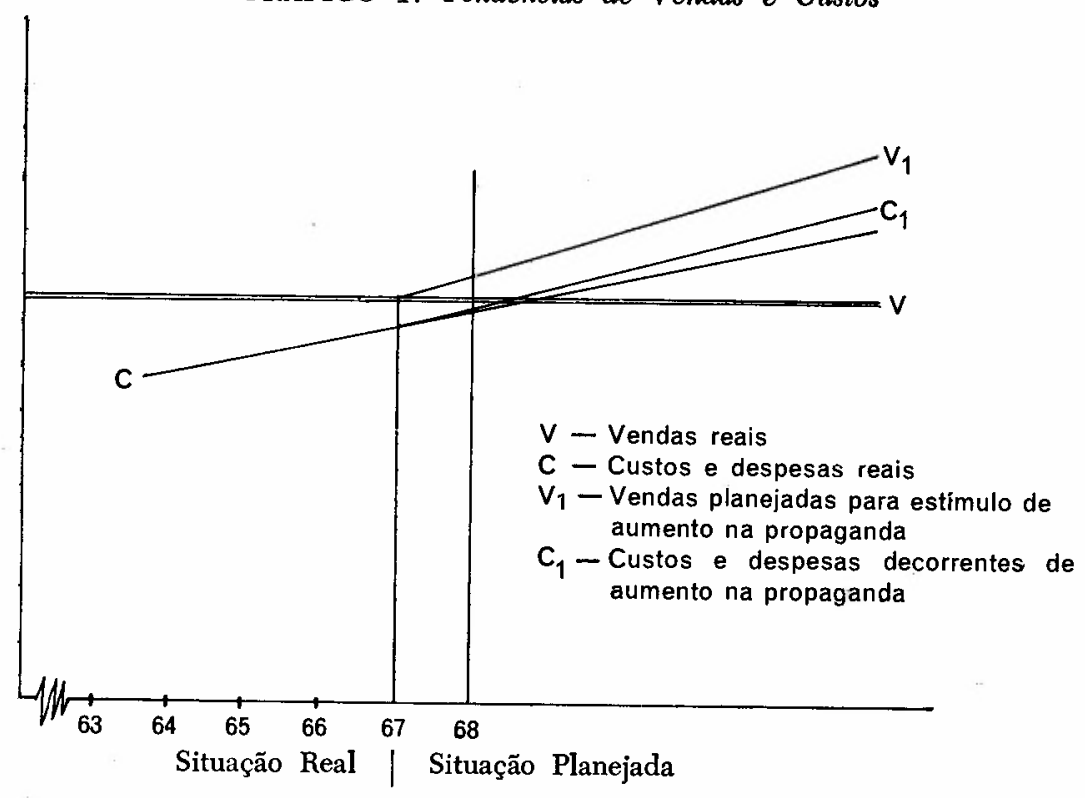

Até fins de 1967, a Cúpula Administrativa da companhia preferira contratar os serviços de uma agência de propaganda; o custeio dêsses serviços fôra feito mediante importâncias fixas inscritas em orçamento, tiradas de um fundo mantido pelos lucros do ano anterior e distribuídas por mês, em igual proporção, englobando a remuneração da referida agência fora os tributos. Assim, uma vez elevados os gastos de propaganda, êstes poderiam representar parte da remuneração da agência.

Levando-se em consideração que em 1966 e 1967 a remuneração da agência de propaganda absorvera apenas 5\% do aumento verificado, no tocante às despesas atualizadas, concluiu a Assessoria Econômica que, nesses anos, a intensificação relativamente pequena da propaganda (de 1965 para 1966) não lograra sensibilizar o público consumidor. 5 Justapondo-se o resultado econômico com a propa-

5 Consigne-se, a propósito, o pensamento de H. W. Pedersen: “... As somas pequenas que se invertem em publicidade pràticamente se perdem: a venda não aumenta em grau apreciável. Se se aumenta gradualmente a soma dedicada à publicidade, o produto marginal da publicidade será, até certo ponto, cada vez maior". (Op. cit., p. 94). 


\begin{tabular}{lcc}
\hline & NCr $\$$ & NCr $\$$ \\
1963 & & \\
1964 & $240.000,00$ & 0,55 \\
1965 & $240.000,00$ & 0,56 \\
1966 & $240.000,00$ & 0,56 \\
1967 & $300.000,00$ & 0,68 \\
\hline
\end{tabular}

ganda, ficava clara a ausência de correlação; estava a companhia ameaçada em sua segurança - mesmo porque, nos anos sob análise, resultado econômico apresentava escala sempre descendente - de $+20 \%$ a $+7 \%$ (Quadro 4). Isto estava a sugerir nova modalidade de propaganda, dinâmica ou talvez agressiva, concomitantemente com os maiores sacrifícios a ela dispensados. $\mathrm{E}$ ante o perigo da maior carga de custos, as vendas deveriam responder sobrelevando-se a ela, quando menos já ao cabo do período experimental (Gráfico 1). Feitos estudos conjuntos pela Divisão de Propaganda, a Divisão de Custos e a Assessoria Econômica, a Cúpula Administrativa aprovou um acréscimo de $\mathrm{NCr} \$ 150.000,00 \mathrm{em}$ gastos de propaganda, sujeitos, naturalmente, a pequenos reajustes.

A Assessoria Econômica, tendo em vista os gastos de propaganda aprovados, procedeu a uma avaliação das vendas no período experimental para as novas manifestações da procura.$^{\circ} \mathrm{A}$ freguesia mais constante preferia, acima de tudo, qualidade. De fato, após dois aumentos de preços, não desanimara. O mais recente havia ocorrido em 1967, passando a unidade de produto a custar NCr $\$ 25,00$, quando, desde meados de 1966, custava NCr $\$ 24,20$. Entre o mês dêste último acrésmimo e o subsequiente, fôra notada uma queda de $3 \%$

- Pôsto que a camada a ser visada pelo nôvo estilo de propaganda era a geração mais jovem de consumidores, teria êle de casar-se com os gostos da juventude. O problema não estaria em oferecer, propriamente, ainda, melhor qualidade. nem barateamento no preço de aquisição do produto. Conviria examinar a sua roupagem, sem prejuízo de certa sobriedade ao gôsto do comprador mais antigo. Dois meses antes, a Divisão de Propaganda completara um estudo com alternativas de propaganda agressiva. 
sôbre o número de vendas previsto. Vencidos três meses a contar do aumento, a freguesia pràticamente se recompôs. Assim, o contingente mensal levado ao mercado, salvo ligeira perturbação, conservara-se rigorosamente - $\mathrm{e}$ as vendas anuais chegaram outra vez a 440.000 unidades, por via de compensação nos derradeiros meses do ano.

Essa pequena fração da procura costumeira (3\%) seria mais sensível à propaganda em sua nova fase, visto que, fôsse como fôsse, reagia em busca de motivação outra, além da simples qualidade superior do produto. Pequena, embora, seu papel talvez viesse a ser bastante funcional em acionar a procura ainda indiferente.

A camada dos consumidores mais jovens, segundo pesquisa feita e estatísticas consultadas, representaria incorporação de 10 a $20 \%$ da freguesia atual. Havia uma particularidade importante em tudo isso: os revendedores poderiam renovar seus pedidos até duas vêzes por mês, com repercussão em mercados circunvizinhos, não só considerados êstes pelas distâncias geográficas, mas, também, pelo caráter de sucedâneo que tinha o produto em relação a outros.

Por ora, assim se distribuía o número de compras mensais da freguesia costumeira: 35.000, de janeiro a outubro, 40.000 em novembro e $50.000 \mathrm{em}$ dezembro. Desenrolando-se a programação no primeiro semestre de 1968, ter-se-ia:

QUADRO 6: Avaliação "Pelo Minimo" da Nova Situação, no Período Experimental

\begin{tabular}{|c|c|c|c|}
\hline $\begin{array}{l}\text { Procura normal; janeiro/ } \\
\text { junho } \\
\text { Procura adicional } \\
\text { Consumidores: }+10 \%\end{array}$ & $\begin{array}{r}210.000 \\
21.000\end{array}$ & $\begin{array}{l}\text { Preço de custo unitário } \\
\text { até } 1968 \\
\text { Acréscimo - Despesa de } \\
\text { propaganda }\end{array}$ & $\begin{array}{l}23,25 \\
0,90^{*}\end{array}$ \\
\hline & 231.000 & \multirow{3}{*}{$\begin{array}{l}\text { Procura adicional } \\
\text { Despesa prevista } \\
\text { Diferença } \\
\\
+\mathrm{NCr} \$\end{array}$} & \multirow{3}{*}{$\begin{array}{r}\times 21.000 \\
509.250,00 \\
15.750,00\end{array}$} \\
\hline $\begin{array}{l}\text { Procura adicional } \\
\text { Preço de venda unitário }\end{array}$ & $\begin{array}{r}21.000 \\
\times 25,00\end{array}$ & & \\
\hline Receita prevista & $525.000,00$ & & \\
\hline NCr\$ Totais & $525.000,00$ & & $525.000,00$ \\
\hline
\end{tabular}

- Valor central unitário de variação, consoante às verbas de propaganda acrescidas. Mostra o Quadro 5 que a despesa média de propaganda com o produto vendido em 1967 alcançava $\mathrm{NCr} \$ 0,68$. 
Decerto, a diferença de $+\mathrm{NCr} \$ 15.750,00$ no semestre correspondente ao período experimental era pouco abonadora para uma empreitada dessa envergadura. Tratava-se, todavia, de avaliação "pelo mínimo", isto é, pelo mínimo que se poderia esperar, sem conter as chamadas "economias internas", provenientes da maior produção e vendas - e outras "externas", por obra da ativação de uma procura elástica.

Em análise da diferença na avaliação "pelo máximo", bem melhores seriam as perspectivas que a segunda frente de propaganda proporcionaria, sustando o declínio da lucratividade; só a procura adicional permitiria lucratividade superior a $10 \%$.

\section{Avaliação dos Resultados}

Uma vez iniciada a campanha no dia marcado, os primeiros resultados não se afastaram muito da antiga situação. Entretanto, à medida

\section{QUADRO 7: Avaliação “Pelo Máximo" da Nova Situação no Periodo Experimental}

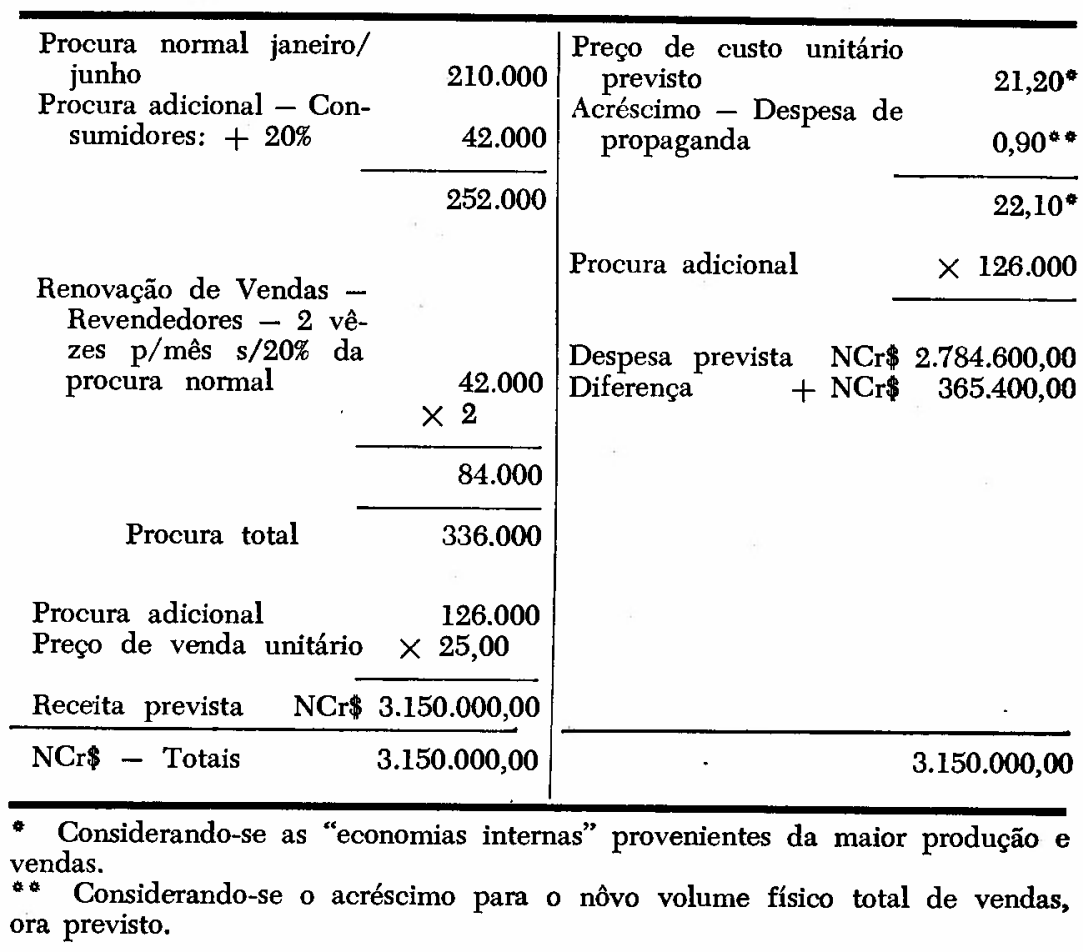


que iam sendo efetuados novos dispêndios em propaganda, dentro do âmbito das diretrizes programadas, notavam-se sinais de reação vindos dos mercados revendedor e consumidor. A Cúpula Administrativa lançava, então, as seguintes questões que, ligadas ao contrôle direto dos efeitos da campanha, deveriam ser respondidas:

a) Qual o grau de eficária da propaganda no estado dos negócios?

b) Quanto tempo deveria durar a campanha além do período experimental?

c) Qual a nova situação do mercado da emprêsa?

QUADRO 8: Montagem Geral dos Dados Atualizados e Reais de 1963 a Junho de 1968, com Acumulativos

\begin{tabular}{cccccccc}
\hline Anos & $\begin{array}{c}\text { Quantidades } \\
\text { Vendidas }\end{array}$ & $\begin{array}{c}\text { Receita } \\
\text { Atualizada }\end{array}$ & $\begin{array}{c}\text { Receita } \\
\text { Média }\end{array}$ & $\begin{array}{c}\text { Receita } \\
\text { Marginal }\end{array}$ & $\begin{array}{c}\text { Custos } \\
\text { Atualizados }\end{array}$ & $\begin{array}{c}\text { Custo } \\
\text { Médio }\end{array}$ & $\begin{array}{c}\text { Custo } \\
\text { Marginal }\end{array}$ \\
\hline
\end{tabular}

\begin{tabular}{|c|c|c|c|c|c|c|c|}
\hline \multicolumn{8}{|c|}{ NCr\$ } \\
\hline $\begin{array}{l}1963 \\
1964\end{array}$ & $\begin{array}{l}440.000 \\
430.000\end{array}$ & $\begin{array}{l}11.000 .000,00 \\
10.750 .000,00\end{array}$ & 25,00 & & $\begin{array}{l}8.800 .000,00 \\
8.815 .000,00\end{array}$ & 20,00 & \\
\hline 1965 & $\begin{array}{l}870.000 \\
425.000\end{array}$ & $\begin{array}{l}21.750 .000,00 \\
10.625 .000,00\end{array}$ & 25,00 & 0 & $\begin{array}{r}17.615 .000,00 \\
9.350 .000,00\end{array}$ & 20,25 & $+0,25$ \\
\hline 1966 & $\begin{array}{r}1.295 .000 \\
440.000\end{array}$ & $\begin{array}{l}32.375 .000,00 \\
11.000 .000,00\end{array}$ & 25,00 & 0 & $\begin{array}{r}26.965 .000,00 \\
9.900 .000,00\end{array}$ & 20,82 & $+0,57$ \\
\hline \multirow[t]{2}{*}{1967} & $\begin{array}{r}1.735 .000 \\
440.000\end{array}$ & $\begin{array}{l}43.375 .000,00 \\
11.000 .000,00\end{array}$ & 25,00 & 0 & $\begin{array}{l}36.865 .000,00 \\
10.230 .000,00\end{array}$ & 21,25 & $+0,43$ \\
\hline & 2.175 .000 & $54.357 .000,00$ & 25,00 & 0 & $47.095 .000,00$ & 21,65 & $+0,40$ \\
\hline 1968 & $\begin{array}{c}\text { Quantidades } \\
\text { Vendidas }\end{array}$ & $\begin{array}{c}\text { Receita } \\
\text { Real }\end{array}$ & $\begin{array}{c}\text { Receita } \\
\text { Média }\end{array}$ & $\begin{array}{c}\text { Receita } \\
\text { Marginal }\end{array}$ & $\begin{array}{l}\text { Custos } \\
\text { Reais }\end{array}$ & $\begin{array}{l}\text { Custo } \\
\text { Médio }\end{array}$ & $\begin{array}{c}\text { Custo } \\
\text { Marginal }\end{array}$ \\
\hline & & NCr\$ & & & & & \\
\hline $\begin{array}{l}\text { jan. } \\
\text { fev. }\end{array}$ & $\begin{array}{l}40.000 \\
35.000\end{array}$ & $\begin{array}{r}1.000 .000,00 \\
875.000,00\end{array}$ & 25,00 & 0 & $\begin{array}{l}856.000,00 \\
752.500,00\end{array}$ & 21,40 & $-0,25$ \\
\hline março & $\begin{array}{l}75.000 \\
45.000\end{array}$ & $\begin{array}{l}1.875 .000,00 \\
1.125 .000,00\end{array}$ & 25,00 & 0 & $\begin{array}{r}1.608 .500,00 \\
958.500,00\end{array}$ & 21,45 & $+0,05$ \\
\hline abril & $\begin{array}{r}120.000 \\
50.000\end{array}$ & $\begin{array}{l}3.000 .000,00 \\
1.250 .000,00\end{array}$ & 25,00 & 0 & $\begin{array}{l}2.567 .000,00 \\
1.060 .000,00\end{array}$ & 21,39 & $-0,06$ \\
\hline maio & $\begin{array}{r}170.000 \\
60.000\end{array}$ & $\begin{array}{l}4.250 .000,00 \\
1.500 .000,00\end{array}$ & 25,00 & 0 & $\begin{array}{l}3.627 .000,00 \\
1.266 .000,00\end{array}$ & 21,34 & $-0,05$ \\
\hline junho & $\begin{array}{r}230.000 \\
70.000\end{array}$ & $\begin{array}{l}5.750 .000,00 \\
1.750 .000,00\end{array}$ & 25,00 & 0 & $\begin{array}{l}4.893 .000,00 \\
1.463 .000,00\end{array}$ & 21,27 & $-0,07$ \\
\hline & 300.000 & $7.500 .000,00$ & 25,00 & 0 & $6.356 .000,00$ & 21,19 & $-0,08$ \\
\hline
\end{tabular}


Sôbre tais questões, a Cúpula Administrativa determinou que a Assessoria Econômica elaborasse um circunstanciado relatório ao fim do período experimental.

Para uma oscilação nas vendas, prevista pela Assessoria Econômica entre 231.000 e 336.000 unidades (Quadros 6 e 7), apuraram-se, na verdade, 300.000 , ao têrmo do semestre dedicado ao plano de propaganda, como logo se verá no Quadro 8 . Por seu turno, o acréscimo real de propaganda no custo do produto vendido variou entre NCr\$ 1,00 e NCr\$1,11 (Quadro 9), tendo a Assessoria Econômica, nesse caso, admitido uma oscilação entre $\mathrm{NCr} \$ 0,90$ e $\mathrm{NCr} \$ 1,10$ (Quadros 6 e 7).

De acôrdo com o Quadro 8, os acumulativos recomeçam no período experimental, à exceção das receitas e custos marginais, que, com as receitas e custos médios (aliás derivados dêsses), vêm a ser os meios informativos automáticos de contrôle e confrontação nas duas fases de aplicação da propaganda. Com fundamento no Quadro 8, são válidas as seguintes observações feitas pela Assessoria Econômica:

a) Para uma receita marginal sempre igual a zero - em vista do preço fixo experimental - os custos, antes da nova fase, eram mais que proporcionais - o que é ditado pelos custos marginais - agravando-se o resultado econômico;

b) Com a dotação de maiores verbas de propaganda da nova fase, os custos, após rápida interrupção em fevereiro, transformaram-se em menos que proporcionais, a favor de um melhor resultado econômico.

Parece haver agora a correlação entre propaganda e resultado econômico, que, anteriormente, era contestada pela insensibilidade do público consumidor. A complementar essa afirmação, verifica-se o declínio da despesa mensal média de propaganda por produto vendido (Quadro 9).

Em seu relatório, a Assessoria Econômica respondeu às perguntas da Cúpula Administrativa da seguinte maneira:

a) Grau de Eficácia da Propaganda no Estado dos Negócios - A despesa média de propaganda declinou; foram absorvidas, no período experimental, 50.000 unidades do produto pelos mercados reven- 
QUADRO 9: Periodo Experimental de Propaganda

- Despesa Média Real de Propaganda por Produto Vendido

Propagand a

\begin{tabular}{lcc}
\hline 1968 & $\begin{array}{c}\text { Despesas } \\
\text { Absolutas }\end{array}$ & $\begin{array}{c}\text { Despesas } \\
\text { Médias }\end{array}$ \\
\hline janeiro & $42.800,00$ & 1,07 \\
fevereiro & $37.600,00$ & 1,07 \\
marco & $50.000,00$ & 1,11 \\
abril & $55.000,00$ & 1,10 \\
maio & $63.300,00$ & 1,06 \\
junho & $70.000,00$ & 1,00 \\
& $318.700,00$ & 1,06 \\
\hline
\end{tabular}

dedor e consumidor, enquanto que, no ano de 1967, a absorção mensal fôra, em média, de 36.666 unidades. (Remissão aos Quadros 1 e 9).

Resultado Econômico por Produto - Em seis meses registrou-se um resultado econômico positivo de $\mathrm{NCr} \$ 1.144 .000,00$, ou seja $15,25 \%$ sôbre a receita de cada produto, contra, apenas NCr $\$ 770.000,00(7,00 \%)$ no ano de 1967 . Os dados comparativos constam no Quadro 10.

QUADRO 10: Periodo Experimental de Propaganda - Comparativos: Resultado Econômico/Crescimento das Receitas e Custos por Produto

\begin{tabular}{|c|c|c|c|c|c|c|}
\hline \multirow{3}{*}{ Anos } & \multirow{3}{*}{$\begin{array}{l}\text { Resultado } \\
\text { Econômico } \\
\text { Atualizado }\end{array}$} & \multirow{3}{*}{$\begin{array}{c}\text { Indice } \\
\text { s/Receita } \\
\text { de Produto }\end{array}$} & \multirow{3}{*}{$\begin{array}{c}\begin{array}{c}\text { Receita } \\
\text { Média }\end{array} \\
\begin{array}{c}\text { Dados A } \\
\text { Acur }\end{array} \\
\text { NCr }\end{array}$} & \multirow{3}{*}{$\begin{array}{c}\text { Despesa } \\
\text { Média }\end{array}$} & \multicolumn{2}{|c|}{ Diferensas } \\
\hline & & & & & \multirow[t]{2}{*}{ Absolutas } & \multirow[t]{2}{*}{ Marginais } \\
\hline & & & & & & \\
\hline $\begin{array}{l}1963 \\
1964 \\
1965 \\
1966 \\
1967\end{array}$ & $\begin{array}{l}+2.200 .000,00 \\
+1.935 .000,00 \\
+1.275 .000,00 \\
+1.100 .000,00 \\
+\quad 770.000,00\end{array}$ & $\begin{array}{r}20,00 \\
18,00 \\
12,00 \\
10,00 \\
7,00\end{array}$ & $\begin{array}{r}25,00 \\
50,00 \\
75,00 \\
100,00 \\
125,00\end{array}$ & $\begin{array}{r}20,00 \\
40,25 \\
61,07 \\
82,32 \\
103,97\end{array}$ & $\begin{array}{r}+\quad 5,00 \\
+\quad 9,75 \\
+\quad 13,93 \\
+\quad 17,68 \\
+\quad 21,03\end{array}$ & $\begin{array}{l}\overline{4,75} \\
4,18 \\
3,75 \\
3,35 \\
\end{array}$ \\
\hline 1968 & $\begin{array}{c}\text { Resultado } \\
\text { Econômico } \\
\text { Real }\end{array}$ & & $\begin{array}{l}\text { Dado } \\
\text { Acur }\end{array}$ & $\begin{array}{l}\text { Reais } \\
\text { ados }\end{array}$ & & \\
\hline $\begin{array}{l}\text { janeiro } \\
\text { fevereiro } \\
\text { março } \\
\text { abril } \\
\text { majo } \\
\text { junho }\end{array}$ & $\begin{array}{ll}+ & 144000,00 \\
+ & 122500,00 \\
+ & 166.500,00 \\
+ & 190.000,00 \\
+ & 234.000,00 \\
+ & 287.000,00\end{array}$ & $\begin{array}{l}14,40 \\
14,00 \\
14,80 \\
15,20 \\
15,60 \\
16,40\end{array}$ & $\begin{array}{l}150,00 \\
175,00 \\
200,00 \\
225.00 \\
250,00 \\
275,00\end{array}$ & $\begin{array}{l}125,37 \\
146,82 \\
168,21 \\
189,55 \\
210,82 \\
232,01\end{array}$ & $\begin{array}{l}+24,63 \\
+\quad 28,18 \\
+\quad 31,79 \\
+\quad 35,45 \\
+\quad 39,18 \\
+\quad 42,99\end{array}$ & $\begin{array}{l}3,60 \\
3,55 \\
3,61 \\
3,66 \\
3,73 \\
3,81\end{array}$ \\
\hline & $+1.144 .000,00$ & 15,25 & & & & \\
\hline
\end{tabular}


Das receitas e custos médios acumulados do Quadro 10 foi elaborado o Gráfico 2 .

b) Tempo de Duração da Propaganda além do Periodo Experimental - Ausentes movimentos cíclicos e quaisquer outras interferências previsíveis, o resultado econômico deveria manter-se ou elevar-se, ainda, presumindo-se que recebesse nôvo impulso, como de hábito, por ocasião das vendas de fim de ano. Por conseguinte, a Assessoria Econômica achava satisfatório o estado dos negócios para o prolongamento do tempo de duração da campanha de propaganda enquanto fôsse possível atestar uma correlação inversa entre índice dos resultados econômicos e despesa média de propaganda.

c) Nova Situação de Mercado - Naturalmente, isso requereria um estudo à parte, baseado em pontos como êstes:

GRAFICO 2: Crescimento das Receitas e Custos por Produto

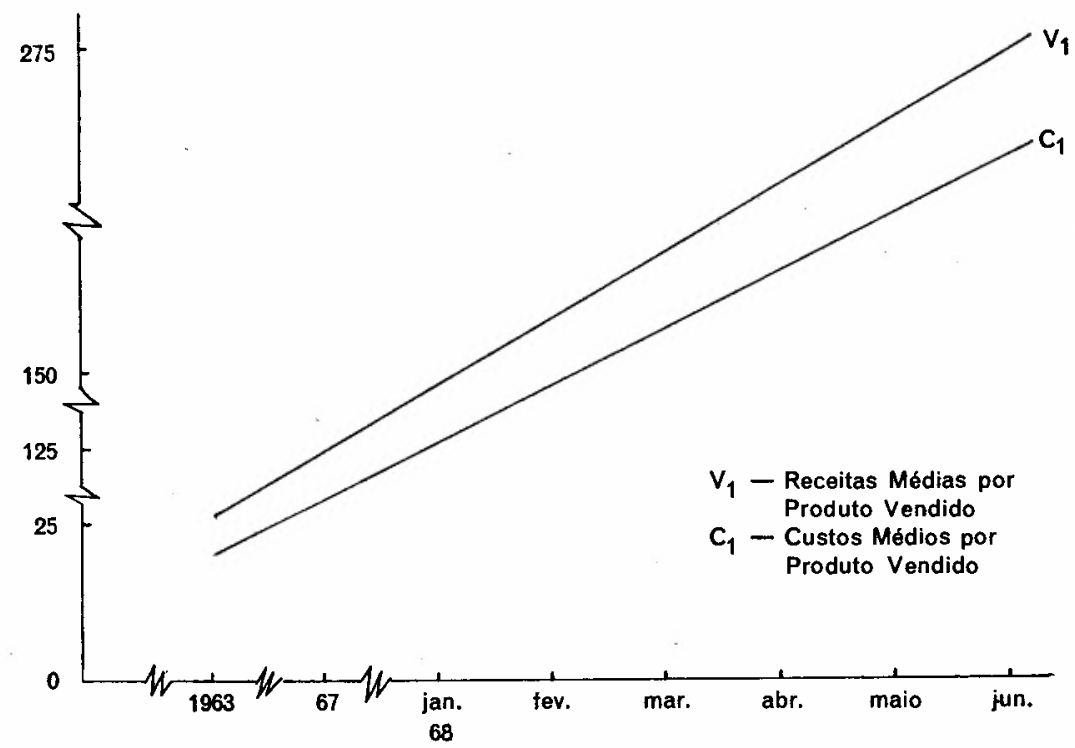

Obs.: No Gráfico 2, os segmentos $V_{1}$ e $C_{1}$ indicam a efetivação da situação planejada do Gráfico 1 , falando-se do êxito da campanha de propaganda no período experimental. 
- procura efetiva anual em relação à companhia;

- percentagem acrescida da produção no mercado (e fixação do consumo aparente);

- percentagem de deslocamento da procura dos demais concorrentes.

A Assessoria Econômica era de parecer que só a conservação da procura - sob a recente incitação psicológica do consumidor não tornaria enganoso o êxito obtido dentro do período experimental, pressentido, entrementes, o alcance dos meios de resistência que, seguramente, seriam postos em prática, sem maior perda de tempo, pelos concorrentes, a respeito de preços, capacidade de produção, distribuição do produto, política de propaganda, etc.

\section{Conclusão}

Efetuando-se o contrôle da propaganda, é da melhor conveniência procurar o ângulo que faculte a visão mais ampla das reações da emprêsa no seu íntimo. Por vêzes, há a comprovar fatos que têm profundidade igual ao agravamento desproporcional dos custos resultantes da maior produção suscitada pelas vendas. A causa poderia estar na movimentação de turmas de trabalho noturno, dentro da conceituação consagrada pela legislação trabalhista, que o admite, mas com remuneração acrescida nunca inferior a $20 \%$ sôbre hora diurna além de outras implicações.

Alguns critérios de contrôle podem pecar pela falta de boa continuidade, com vistas a traçar-se segura política de propaganda.

Neste caso, existe certa insuscetibilidade não teórica dos índices de correlação bivariada, simples, entre propaganda e vendas, em dar a medida das aplicações regulares em gastos de propaganda, utilizados, então, como meio subsidiário na condução das mesmas .

Para mais de um produto coberto por propaganda deve haver um contrôle específico. Por outro lado, nenhum critério de fundo econômico sugeriria a inflexibilidade dos preços de venda como artifício técnico indispensável a realizar o contrôle. No caso ora exposto, tornava-se notória a atitude de cortar uma perturbação do efeito que se esperava da campanha de propaganda, no curso de condições que causavam séria apreensão, e nas quais a alternativa viável era a procura do produto. 